\title{
Peningkatan Nilai Jual Biji Mete Hasil Produksi Masyarakat Desa Gumantar Kabupaten Lombok Utara
}

\author{
Ade Putra Kurniawan ${ }^{1)}$, Ferly Eka Kerniati ${ }^{2)}$, Andre Rachmat Scabra*3) \\ ${ }^{1)}$ Program Studi Peternakan, Fakultas Peternakan Universitas Mataram \\ ${ }^{2)}$ Program Studi Ilmu Pendidikan, Fakultas Keguruan dan Ilmu Pendidikan Universitas Mataram \\ ${ }^{3)}$ Program Studi Budidaya Perairan, Fakultas Pertanian Universitas Mataram
}

\section{Article history}

Received: 15 Maret 2020

Revised: 25 Maret 2020

Accepted: 11 Mei 2020

*Corresponding Author:

Andre Rachmat Scabra

Program Studi Budidaya

Perairan

Fakultas Pertanian

Universitas Mataram,

Mataram, NTB,

Indonesai;

Email:

andrescabra@unram.ac.id.
Abstract: Gumantar Village is one of the villages in North Lombok Regency which has quite good potential in the agriculture and plantation sectors. One of the agricultural products in Gumantar Village is Cashew seeds. The community of Gmumantar Village is not yet optimal in terms of cashew nut processing. Cashew seed products harvested through plantations are sold in raw condition to collectors. Penagbdian activities to the community aims to increase the sale value of processed cashew seed products in Gumantar Village, North Lombok Regency. The increase in selling value is done by processing cashew seeds into ready-to-eat food products. The method of activities carried out is by conducting surveys, training, assistance and evaluation. Partners in community service activities are community groups that are part of the "Cashew series" cashew processing group in Guantar Village, North Lomok Regency. The results that have been achieved from this activity are increased public knowledge about how to process cashews into cashews to increase family income. Cashew seeds sold in raw conditions can now be processed into products that have a higher economic value. The name of the product produced in this community service is "Gumantar Cashew Nuts".

Keywords: processed; cashew; accompaniment; product; economy

Abtrak: Desa Gumantar merupakan salah satu desa pada kabupaten Lombok Utara yang memiliki potensi yang cukup baik pada sektor pertanian dan perkebunan. Salah satu produk hasil pertanian pada Desa Gumantar adalah biji Mete. Masyarakat Desa Gmumantar belum optimal dalam hal pengolahan biji mete. Produk biji mete yang dipanen melalui perkebunan dijual dalam kondisi mentah kepada para pengepul. Kegiatan penagbdian kepada masyarkat ini bertujuan untuk meningkatakn nilai jual produk olahan biji mete di Desa Gumantar Kabupaten Lombok Utara. Peningkatan nilai jual tersebut dilakukan dengan melakukan kegiatan pengolahan biji mete menjadi produk makanan siap saji. Metode kegiatan yang dilakukan adalah dengan melakukan survey, pelatihan, pendampingan dan evaluasi. Mitra pada kegiatan pengabdian kepada masyarakat ini adalah kelompok masyarakat yang tergabung dalam kelompok pengolah Mete "mete berseri" Desa Guantar Kabupaten Lomok Utara. Hasil yang telah dicapai dari kegiatan ini adalah meningkatnya pengetahuan masyarakat tentang bagaimana mengolah biji mete menjadi kacang mete untuk meningkatkan pendapatan keluarga. Biji mete yang dijual dalam kondisi mentah kini telah dapat diolah menjadi produk yang memiliki nilai ekonomis lebih tinggi. Nama produk yang dihasilkan pada kegiatan pengabdian kepada masyarakat ini adalah "Kacang Mete Gumantar".

Kata kunci: olahan; mete; pendampingan; produk; ekonomi 


\section{PENDAHULUAN}

Desa Gumantar merupakan salah satu desa yang terletak di kecamatan Kayangan, kabupaten Lombok Utara, Provinsi Nusa Tenggara Barat yang memiliki ciri khas, dimana banyak didominasi oleh sektor pertanian dan perkebunan. Tetapi, sumber daya alam yang dimiliki oleh desa Gumantar kurang mampu menaikan taraf hidup masyarakatnya dikarenakan pemanfaatan potensi sumber daya yang belum optimal. Belum maksimalnya pemanfaatan terhadap potensi sumbedaya alam tersebut disebabkan oleh terbatasnya informasi dan pengetahuan mesyarakat dalam teknik pengolalaannya sehingga mengalami perkembangan yang lambat ditambah lagi dengan terjadinya gempa beberapa waktu yang lalu yang menyebabkan kondisi perekonomian masyarakat semakin menurun. Selain itu, dilihat dari pola kehidupan masyarakat desa Gumantar dimana kelompok ibu-ibu rumah tangga yang hampir seluruhnya tidak berpenghasilan atau menganggur dikarenakan latar belakang pendidikan yang minim dan kurangnya keterampilan yang dimiliki.

Kesadaran diri masyarakat desa Gumantar terhadap potensi sumber daya alam yang dimiliki serta pentingnya menjaga sumber daya alam sangat tinggi, akan tetapi tidak memiliki dukungan sumberdaya manusia yang kompeten untuk mengelolanya. Maka melalui proses diskusi dan observasi, tim pelaksanan kegiatan pengabdian kepada masyarkat berusaha membantu menemukan jalan keluar bersama masyarakat setempat. Salah satu solusi yang menjadi perhatian kami adalah bagaimana mengolah biji mete ini menjadi suatu produk yang memiliki nilaijual lebih tinggi jika dibandingkan dengan biji mete dalam kondisi mentah.

Potensi sumber daya yang dimiliki berupa biji mete yang menjanjikan untuk dikembangkan. Pengolahan dengan skala agroindustri rumahan perlu dilakukan untuk memanfaatkan sumber daya manusia terutama perempuan atau ibu rumah tangga dimana dilakukan pendekatan industri rumahan untuk memproduksi olahan mete yang memiliki kandungan gizi dan nilai jual serta memiliki daya saing. Dengan pengolahan biji mete skala agroindustri rumahan ini, diharapkan masyarakat Pengolah biji mete Desa Gumantar mendpatakan tambahan nilai ekonomis sehingga dapat meningkatkan taraf kesejahteraan.

Kendala utama dalam memproduksi adalah masih kurangnya pengetahuan masyarakat untuk mengolah biji mete tersebut. Melihat adanya petensi besar yang ada di Desa Gumantar dengan banyaknya ketersediaan biji mete dan ketersedian alat sarana dan prasarana seperti kacip dan oven serta kelompok usaha maka timpelaksana kegiatan pengabdian kepada masyarakat mengadakan berbagai kegiatan untuk mengatasi permasalah tersebut. Diharapkan dari program yang kami buat dapat membantu masyarakat untuk mengolah biji mete yang melimpah ketika musimnya.

\section{METODE}

\section{Alat dan bahan}

Alat yang digunakan dalam pembuatan kacang mete adalah Kacip, baskom, pisau, wajan, spatula, dan oven. Bahan yang digunakan adalah biji mete, coklat, minyak, garam, dan perasa balado.

\section{Pelatihan Produksi dan Sosialisasi Kacang mete}

Prosedur kerja produksi dan sosialisasi pengolahan biji mete:

1. Beraudiensi dengan warga sekitar.

Audiensi ini kami lakukan dengan tujuan untuk mencari tau tentang karakter dari warga sehingga akan memudahkan dalam pelaksanaan kegiatan. Kami mendengarkan permasalhan yang dialami, sehingga kami bisa mengambil langkah yang tepat untuk mencaro solusi atas permasalahan tersebut.

2. Mempersiapkan lokasi sosialisasi.

Lokasi sosialisasi dan pelatihan dipersiapkan dengan baik, yaitu dengan melakukan pembersihan, penataan kursi dan meja, penyediaan sarana dan prasarana yang diperlukan, dan lain lain sebaginya. Pelaksaan kegiata ini kami atur agar dapat berjalan dengan nyaman sehingga materi yang disampaikan dapat diterima dengan baik.

3. Mempersiapkan alat dan bahan. 
Persiapan alat dan bahan berupa pengecekan keberfungsiannya. Apabila terdapat alat yang tidak berfungsi dengn baik, maka akan diperbaiki terlebih dahulu sebelum kemudian digunakan pada saat pelaksanaan kegiatan berlangsung.

4. Pelatihan pengolahan kacang mete.

Pelatihan ini dilakukan dengan seksama, yaitu mempertimbangkan status kependidikan masyarakat pada Desa Gumantar. Kami menggunakan bahasa yang mudah difahami, juga tutur kata dan perilaku yang lembut. Hal tersebut berhasil mendapatkan perhatian dan sambutan yang baik dari masyarakat Desa Gumantar.

5. Pengurusan perijinan produk

Perijinan produk berupa PIRT kami usulkan kepada dians pemerintah terkait. Pengurusan PIRT ini kami rasa perlu untuk dilakukan karena berdasarkan Yulianti dan Mustarichie (2018), UMKM yang bergerak di bidang indutrsi makanan masih belum memiliki izin PIRT sekitar 33,95\%. Hal tersebut berdampak terhadap tidak bisanya hasil produk UMKM tersebut dipasarkan dalam ruang lingkup yang lebih luas.

\section{HASIL DAN PEMBAHASAN}

Kegiatan pelatihan pembuatan kacang mete dimulai dengan mempersiapkan program yang terdiri dari observasi, dan wawancara. Berdasarkan hasil wawancara dan observasi terdapat beberapa hal yang ditemukan antaranya adalah:

1. Kegiatan pengolahan biji mete di Desa Gumantar telah dilakukan oleh pemerintah kabupaten, pusat, maupun isnstitusi pendidikan. Kegiatan penagbdian kepada masyarakat yang dilakukan ini merupakan bentuk tindak lanjut dari kegiatan yang dilakukan sebelumnya. Pemberian bantuan berupa peralatan kerja dilakukan oleh pemerintah, penggunaan dan pengoperasionalan bantuan tersebut dilakukan melalui kegiatan pengabdian kepada masyarakat ini.

2. Melalaui kegiatan pengabdian kepada masyarakat, penggunaan peralatan berupa oven dan kacip menjadi lebih intensif untuk digunakan. Berdasarkan Mulyono (2007), beberapa hal yang perlu diperhatikan dalam proses pengacipan mete agar diperoleh produk yang memenuhi persyaratan mutu (utuh, bersih, mulus) dan produktivitasnya tinggi, yaitu :

a. fasilitas dan pengawasan terhadap kebersihan/higienis pengerjaan sehingga pekerja dan kernel terkupas tidak terkontaminasi CNSLdan kotoran lain,

b. Membuang/memisahkan hasil kupasan yang busuk atau rusak agar tidak tercampur dengan hasil kupasan yang baik, dan

c. Selama pengacipan tangan pekerja/operator harus memakai alat pelindung (sarung tangankaret) agar terhindar dari pengaruh buruk cairan kulit (CNSL) karena dapat membuatkulit teriritasi.

Bahan-bahan yang diperlukan dalam proses pelatihan pembuatan kacang mete adalah: biji mete, air panas, garam, coklat, perasa balado, minyak goreng, dan kertas minyak. Alat yang diperlukan adalah: kacip, baskom, wajan, silet, sarung tangan, pisau, dan kompor. Dalam pembuatan produk ini, semua bahan telah di persiapkan oleh tim pelaksana kegiatan pengabdian kepada masyarakt sedangkan sebagian kacip telah tersedia oleh kelompok usaha setempat. Tahap selanjutnya adalah pembukaan pelatihan. Pelatihan ini dihadiri oleh beberapa pihak diantaranya adalah kepala desa, tokoh agama setempat, masyarakat, dan juga kelompok UMKM desa. 


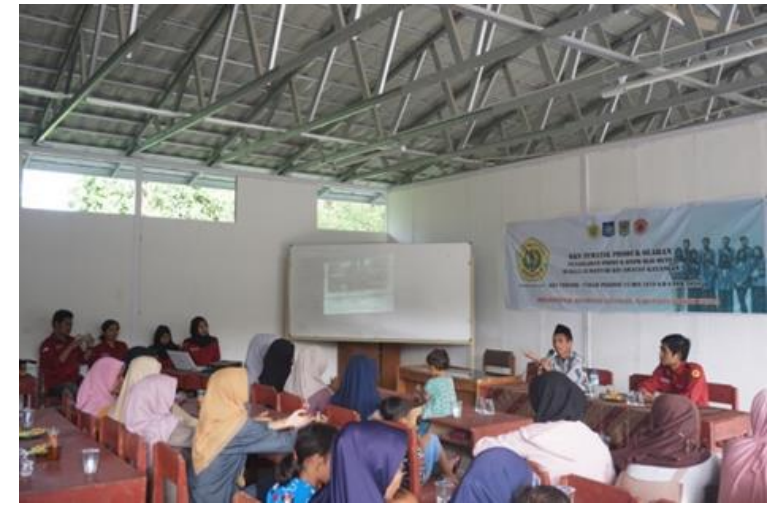

Gambar 1. Sosialisasi yang dihadiri oleh warga setempat

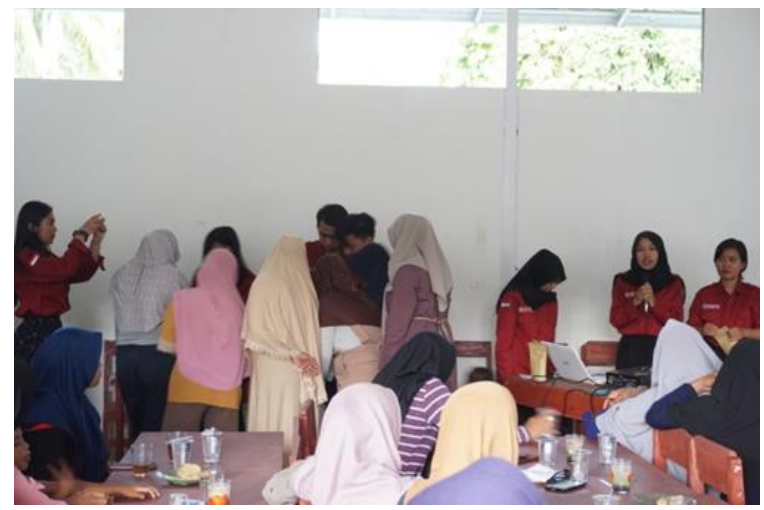

Gambar 2. Pemeparan materi sekaligus praktek langsung

Pelatihan pembuatan kacang mete diawali dengan menyanyikan lagu Indonesia Raya Dilanjutkan dengan pemaparan materi oleh pemateri dilanjutkan dengan praktek langsung yang melibatkan seluruh peserta pelatihan. Proses produksi kacang mete melalui baberapa tahap yaitu:

1. Memisahkan mete (buah sejati) dengan daging (buah semu).

Buah sejati (mete) dan buah semu (daging) harus dipisahkan terlebih dahulu. Cara pemisahannya cukup gampang yaitu dengan cara memutar buah sejatinya dengan dagingnya sampai terputus, setelah itu hasilnya di tempatkan pada wadah yang terpisah. Selanjutnya cuci mete tersebut supaya bersih dari kotoran, debu, pasir dan lain-lain.

2. Sortir dan grading

Mete yang sudah dipisahkan dari daging (buah semu) kemudian dilakukan sortir, yaitu memisahkan mete gelondong yang baik dengan mete gelondong yang jelek atau busuk dan dilakukan grading, yaitu mengelompokkan mete gelondong menurut ukuran.

3. Pengeringan mete gelondong

Mete gelondong harus dikeringkan karena diperkirakan dalam mete gelondong terdapat kadar air sebanyak 25\%. Pengeringan dilakukan supaya keping biji tidak mengalami kerusakan baik kerusakan yang dilakukan oleh jamur, bakteri maupun faktor enzimatis lainnya. Pengeringan dilakukan bertujuan untuk mempertahankan kualitas juga memudahkan dalam pengupasan.

4. Penyimpanan mete gelondong

Yang perlu diperhatikan ketika melakukan penyimpanan yaitu suhu udara dan kelembaban udara. Diusahakan tempat penyimpanan mete gelondong ini yang mempunyai susu udara yang tinggi karena selama penyimpanan ini masih terjadi proses pengeringan.

5. Pengambilan kacang mete

Kacang mede yang diambil dari cangkangnya bisa menggunakan cara manual maupun mekanis. Cara manual biasanya dilakukan dengan dipukul. Sedangkan cara mekanis menggunakan mesin, biasanya hasilnya lebih bagus kacang metenya utuh $90 \%$.

6. Pengeringan kacang Mente

Kacang mede dikeringakan supaya mudah dalam mengelupas kulit arinya serta mencegah adanya serangan hama dan juga meningkatkan daya simpan kacang mete. Pengeringannyabisadilakukan menggunakan sinar matahari maupun menggunakan oven. Pengeringan itu sendiri tidak boleh berlebihan karena akan membuat kacang mente menjadi rapuh yang menyebabkan kacang mete mudah pecah.

7. Pengupasan kulit ari

Pengupasan kulit ari ini bisa dilakukan dengan cara penggesekan dengan tangan maupun menggunakan pisau. Pengupasan kulit ari ini harus dilakukan dengan hati-hati agar tidak melukai kacang mente dan tidak mengurangi mutu kacang mete

8. Sortasi dan grading kembali 
Sortasi dan grading pada kacang mete perlu dilakukan kembali sebelum dijual hal ini dilakukan untuk menyeragamkan kacang mete menurut kualitasnya dan memudahkan dalam menentukan harga jual.

Biji mete yang telah melalaui serangkaian proses persiapan kemudian diolah menjadi produk makanan siap konsumsi. Pengolah tersebut dilakukan dengan cara menggoreng dan membumbui biji mete sesuai dengan peasa makanan yang diinginkan. Hasil dari pelatihan ini berupa kacang mete dengan berbagai rasa diantaranya rasa original, rasa balado, dan juga rasa coklat. Kemudian dilakukan pengemasan kedalam wadah dengan berat masing-masing 100 gr. Setelah itu ditempelkan stiker yang memuat informasi produk.

UU no 36 tahun 2009 tentang kesehatan menyatakan bahwa setiap makanan dan minuman hanya dapat diedarkan setelah mendapat izin edar. Oleh karena itu, tim pelaksana kegiatan pengabdian kepada mayarakat melakukan pengurusan perizinan edar prdoduk mete melalaui dinas pemerintahan terkait, yaitu Dinas Kesehatan Kabupaten Lombok Utara. Pengrusan sertifkat P-IRT dilakukan berdasarkan mekanisme yang diatur pada Peraturan Badan Pengawas Obat dan Makanan nomor 22 tahun 2018 tentang pedoman pemberian sertifikat produksi pangan industri rumah tangga.

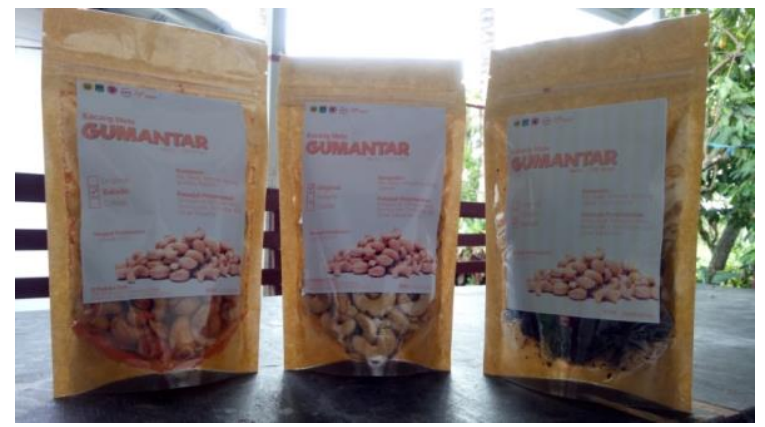

Gambar 3. Produk biji mete hasil olahan

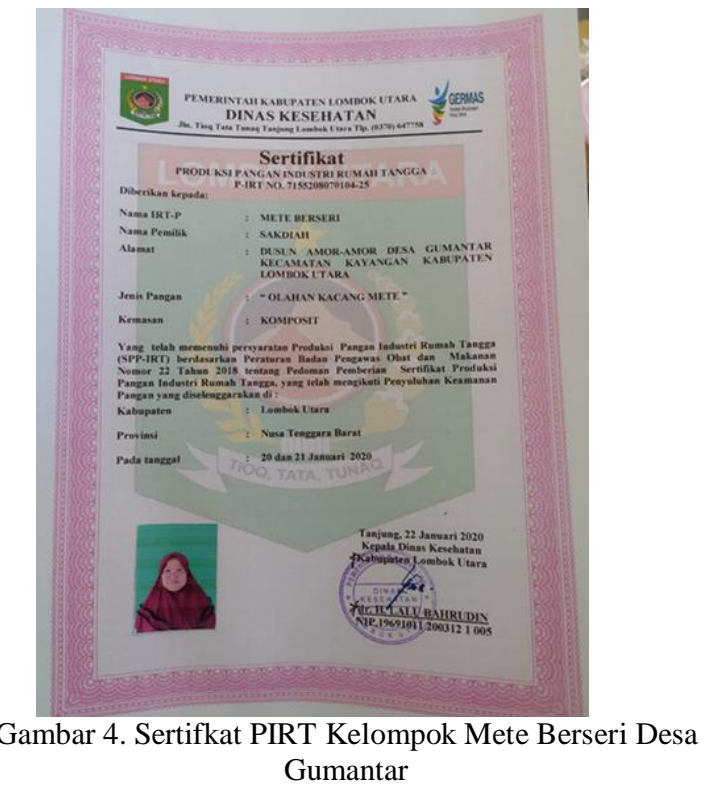

Gumantar

\section{KESIMPULAN DAN SARAN}

Kegiatan ini telah berhasil meningkatkan pengetahuan masyarakat dalam pengolahan biji mete melalaui terbentuknya sebuah produk makanan siap konsumsi berbasis biji mete tang bernama "kacang mete Gumantar".

\section{Ucapan Terima Kasih}

Terima kasih penulis ucapkan kepada teman-teman yang sudah menyumbangkan ide dan keringan sehingga kegiatan yang dilakukan dapat berjalan dengan baik dan lancar yang telah, diselanggarakan oleh oleh tim tim pelaksana kegiatan pengabdian kepada masyarakt Univertas Mataram periode 2020 antara lain: Dinas Kesehatan Kabupaten Lombok Utara, Kepala Desa Gumantar, Masyarakat Desa, dan Kelompok UMKM Desa. 


\section{DAFTAR PUSTAKA}

Mulyono, Edi. 2007. Teknologi Pengolahan Mete. Bogor: Balai Besar Penelitian dan Pengembangan Pasca Pertanian.

Peraturan Kepala BPOM Nomor 03.1.23.04.12.2205 tahun 2012 tentang Pemberian Sertifikat Produksi Pangan Industri Rumah Tangga

Presiden Republik Indonsia. 2009. Undang-Undang RI Nomor 36 Tahun 2009 Tentang Kesehatan. Jakarta: Presiden Republik Indonesia.

Yulianti MD, Mustarichie R. 2018. Tata Cara Registrasi Untuk Pangan Olahan Industri Rumah Tangga (Pirt) Dan Makanan Dalam Negeri (Md) Dalam Rangka Peningkatan Produk Yang Aman Dan Bermutu Di Bandung Jawa Barat. Farmaka Volume 15 Nomor 3 hal 57-64. 